\title{
RELAÇÕES DE GÊNERO E VIOLÊNCIA CONTRA MULHERES INDÍĠENAS EM AMAMBAI - MS (2007-2013)
}

TÂNIA REGINA ZIMMERMANN ${ }^{1}$

$U E M S$

LAURIENE SERAGUZA ${ }^{2}$

UEMS

ANA EVANIR ALVES VIANA ${ }^{3}$

UEMS

\begin{abstract}
RESUMO: Esta pesquisa objetiva entender algumas formas de violência perpetradas contra mulheres indígenas em reservas no município de Amambai (MS) a partir de 2007 até 2013. Na questão de gênero, as mulheres indígenas estão entre as mais gravemente afetadas por violências múltiplas e permanecem na perspectiva da vitimização. Através da metodologia da história oral, realizamos entrevistas com mulheres indígenas vítimas da violência masculina bem como com pessoas envoltas (capitão, gestora da Coordenadoria da Mulher de Amambai e pesquisadoras da temática indígena kaiowá) nessas situações de conflito, além do levantamento de boletins de ocorrência. Destarte, torna-se importante uma pesquisa que evidencie alguns silêncios dessas mulheres, e que dê visibilidade e dizibilidade às formas de violência doméstica exercidas contra mulheres indígenas da região a partir da perspectiva de gênero, bem como observe perspectivas das próprias mulheres indígenas para dirimir esta violação.
\end{abstract}

PALAVRAS-CHAVE: relações de gênero; mulheres indígenas; violência.

ABSTRACT: This research aims to understand some forms of violence perpetrated against women in indigenous villages in the municipality of Amambai, MS from 2007 to 2013. Regarding the gender issue, indigenous women are among the most severely impacted by multiple forms of violence and remain in the perspective of victimization. Interviews were conducted with indigenous women victims of domestic violence as well as with people involved in these conflict situations (the captain, the manager of the Amabai's public office for women and researchers of the subject). Thus, it becomes important academic research that highlights the silent these women live by and produces visibility to the forms of domestic violence

\footnotetext{
${ }^{1}$ Pós-doutora em História pela Universidade Federal do Paraná e professora do curso de História e da pós-graduação da Universidade Estadual do Mato Grosso do Sul. E-mail: zimmermanntania@hotmail.com.

${ }^{2}$ Mestre em Antropologia pela Universidade Federal da Grande Dourados e professora do curso de Ciências Sociais da Universidade Estadual do Mato Grosso do Sul. E-mail: laurieneseraguza@yahoo.com.br.

3 Graduada em Ciências Sociais pela Universidade Estadual do Mato Grosso do Sul. E-mail: taniazimmermann@gmail.com .
} 
perpetrated against these indigenous women, an academic research from the gender perspective that notices these indigenous women's own perspectives to resolve this violation.

KEYWORDS: gender relations; indigenous women; violence.

A partir de uma perspectiva de gênero, se observou situações de violência contra mulheres indígenas ${ }^{4}$ perpetradas em duas reservas de Amambai, no Estado do Mato Grosso do Sul (Limão Verde e Amambai), desde 2007, ano que marca os começos dos registros de violência contra a mulher na delegacia local, até 2013. Além do depoimento de mulheres vítimas de violência doméstica levantamos 63 casos dessa violência nos boletins de ocorrência, dos quais 14 se configuram em estupro somando-se a um atentado ao pudor. As demais ocorrências eram de violência doméstica, resultando em 5 mortes de mulheres.

O termo violência é compreendido como uma intervenção que causa dano físico ou moral com a finalidade de destruir, ofender, coagir, torturar, ferir e/ou matar contra a vontade da vítima e impede a pessoa de cumprir determinada ação5. O conceito "violência contra a mulher" tem uma acepção mais vasta e permite tratar atos violentos no interior da conjugalidade. Já o termo "violência de gênero" é transversal às demais violações, pois inclui também a violência contra crianças e adolescentes, bem como entre mulheres e entre homens. Esse termo também sobrepõe outros conceitos, como "violência doméstica e familiar". A violência doméstica é uma das principais formas de violação feminina, pois o lar é o lugar onde as mulheres correm mais riscos.

A aproximação com estes coletivos étnicos ${ }^{6}$ permitiu uma conversa inicial sobre os seus posicionamentos em relação à violência perpetrada contra as mulheres. As falas de mulheres geralmente tímidas

\footnotetext{
${ }^{4}$ Foram realizadas onze entrevistas pela acadêmica Ana Evanir Alves Viana com mulheres indígenas de ambas as aldeias e seus nomes serão preservados.

${ }^{5}$ Ver Bobbio, Matteucci e Pasquino (1998).

${ }^{6}$ Em seus estudos sobre os povos Piaroa, Joanna Overing (1999, p. 87) considera que os coletivos étnicos referem-se a "apego a um modo de ser social e culturalmente específico". E segundo Seraguza (2013, p. 16), "esses coletivos que produzem uma política terrena, correlacionada com a convivialidade, e uma política cósmica relacionada às práticas rituais e ao xamanismo".
} 
e às vezes interrompidas pela emoção, tristeza e indignação foram de grande relevância na tessitura deste texto.

Os espaços ocupados pelos coletivos indígenas nas reservas ${ }^{7}$ Limão Verde e Amambai advêm de um processo de expropriação territorial ao qual foram submetidos historicamente no Mato Grosso e Mato Grosso do Sul. Esse processo é acelerado após os contatos com a população que se estabeleceu na região a partir das ações exploratórias da Companhia Matte Larangeira, e posteriormente o confinamento iniciado pelo Serviço de Proteção aos Índios (SPI). Assim sendo, reservas indígenas foram instituídas no Brasil desde o final do século XIX e seguiram até a segunda metade do século XX. Nos anos de 1940, a política agrária de Getúlio Vargas também criou reservas indígenas a fim de obter mais terras para os colonizadores no Estado do Mato Grosso (BRAND, 1997; PEREIRA, 1999). Porém, entre as décadas de 1940 a 1970, várias aldeias kaiowá e guarani foram invadidas por fazendeiros, os quais expulsaram seus ocupantes indígenas. A partir desse período grande parte dessa população foi transferida para reservas, enquanto outras passaram a perambular em espaços como beira de estradas e fazendas vizinhas.

Segundo Katya Vietta (2001), a população indígena kaiowá e guarani no Mato Grosso do Sul é superior a 45.000 pessoas, dispersas em 34 Terras Indígenas (TI) e reservas. No estado, 8 reservas foram demarcadas entre 1915 e 1928, e outras aldeias reocupadas a partir da década de 1980. Segundo Vietta, “(...) a fisionomia do território disponível para esta população foi profundamente alterada em um período bastante recente e relativamente curto" (VIETTA, 2001, p. 90).

O Município de Amambai soma aproximadamente 38.000 habitantes e situa-se ao sul do Estado do Mato Grosso do Sul. No seu entorno instituiu-se as reservas indígenas Amambai, Limão Verde e Jaguari, somando uma população de quase 9.000 indígenas de diferentes etnias (Guarani e Kaiowá), conforme os dados da coordenadoria da Fundação Nacional do Índio (Funai) no município. A reserva Amambai possui uma área de 2.429 ha e uma população de 7.110 habitantes. A reserva Limão Verde conta com uma área de 608 ha

\footnotetext{
7 Nesta pesquisa usaremos o termo "reservas" e "terras indígenas", pois são noções advindas com a legislação fundiária e os processos demarcatórios (este último desde a Constituição Federal de 1988).
} 
e em torno de 1.600 habitantes indígenas 8 . Percebe-se pelo tamanho destas áreas que as terras são exíguas e limitam a capacidade destes coletivos étnicos gerirem seus recursos e manter os seus modos de vida tradicionais.

A criação de reservas naquela região visando aldear os coletivos kaiowá e guarani9 de Mato Grosso do Sul não se referia aos seus tekoha10 tradicionais, cuja categoria aldeia referia-se espaços instituídos, ou seja, uma abstração criada pelo estado brasileiro para diferenciar os índios aldeados dos não aldeados. Estes últimos seriam concebidos como marginais e não merecedores da tutela estatal. Naquele estado, indígenas não aldeados foram encontrados em estâncias, restos de bosques, beira de estradas e cidades ${ }^{11}$. Com o confinamento de indígenas em pequenos lotes, mais terras estavam disponíveis para a aquisição de proprietários privados e também liberaria espaços para abrir estradas, estâncias e povoados não indígenas.

Porém, nesse processo de confinamento, a população das reservas crescia numericamente e os modos de vida não comportavam os seus modelos organizacionais. Em consequência disso, conflitos políticos, sociais, religiosos, econômicos e de gênero tornaram-se latentes e crescentes. Somam-se a isso problemas como a desnutrição, doenças, suicídio e violência como aspectos bárbaros deste processo de aldeamento.

É importante ressaltar que essas mudanças e problemas sociais advêm das mudanças nos vários módulos organizacionais que viviam num sistema de coletividade em espaços maiores; assim, muitos indígenas que nasceram depois desse processo de confinamento contínuo não conheceram a cultura tradicional de seu coletivo étnico.

\footnotetext{
${ }^{8}$ Dados obtidos junto ao escritório regional da Funai de Amambai. Os dados são de 2014.

${ }^{9}$ Pereira (2008, p. 3) observa que há muita confusão ao denominar os grupos étnicos no MS apenas pela classificação linguística, por isso, a nominação Kaiowá e Guarani leva em consideração o sistema de autodeterminação posto na Constituição Federal de 1988.

${ }^{10}$ Os tekoha tradicionais referem-se a uma unidade básica da organização social, na qual existe um conjunto de valores associados às relações de parentesco. Estas práticas ocorrem no território que ocupam, ou melhor, o local onde se concebem e se localizam tais relações (MELIÁ, GRÜNBERG e GRÜNBERG, 1976, p. 218). Atualmente esta noção está muito mais inscrita nas relações sociais do que espaciais, conforme discutem Pereira (2008) e Vietta (2007).

${ }^{11}$ Conforme entrevista concedida por Graciela Chamorro à Revista Espaço Ameríndio (FELIPE e PAZ, 2011).
} 
Cabe observar que as formas de organização social kaiowá e guarani e as circunstâncias vividas na atualidade são similares em ambas as reservas. A maior parte destas populações aldeadas é do coletivo indígena kaiowá.

$\mathrm{Na}$ atual situação vivida pelas famílias nas duas reservas, novas interações, advindas das transformações e mudanças provocadas com o contato não indígena, recolhimento das populações em áreas pequenas, o trabalho temporário dos homens fora da reserva, a profissionalização de mulheres, a diminuição de práticas xamânicas e de rituais, a degradação da paisagem natural e a introdução de drogas e bebidas alcoólicas dos não indígenas nestas comunidades reservadas, redefinem as relações de gênero, que se tornam-se conflitivas e por vezes violentas.

Nesse contexto, os atributos culturais associados às tarefas e espaços masculinos e femininos realocaram as posições de prestígio e de status para ambos. Essa realocação pode ser conflitiva nas relações de gênero. Segundo entrevista com Vietta, historicamente a violência nos coletivos indígenas era pequena e, quando existente, controlada nos diferentes módulos organizacionais:

[...] em períodos mais recuados, os níveis de violência nas aldeias eram extremamente baixos e isso serve tanto para os kaiowá como para os guarani, como para outras populações indígenas. Porque essa sociedade tinha formas de controle (...). Primeiro, antes dessas questões eram sociedades que tinham uma situação de equilíbrio social, econômico e político bastante consistente (Entrevista com Katya Vietta, 11 jun. 2014) $)^{12}$.

Isso nos mostra que havia violência antes da colonização branca europeia entre os indígenas. Smith, embora se refira ao contexto estadunidense, observa que "(...) tanto os registros orais quanto escritos frequentemente mostram que ela é relativamente rara, assim como a severidade na punição para os perpetradores de violência" (SMITH, 2014 , p. 209). Esta assertiva também se fazia presente entre os coletivos indígenas do Mato Grosso do Sul.

\footnotetext{
${ }^{12}$ Entrevista concedida a Ana Evanir Alves Viana.
} 
Sobre a organização dos módulos organizacionais e o controle de práticas de violência, Vietta destaca as importantes estratégias das pessoas mais velhas na articulação política e religiosa nos coletivos étnicos guarani e kaiowá:

\begin{abstract}
As populações se organizam a partir das relações de parentesco. As lideranças se estabelecem também a partir das relações de parentesco (...). Então a família era um grupo grande, um grupo coeso. Era um grupo muito bem articulado onde as questões de violência eram praticamente exceções. Eventualmente uma briga entre irmãos, cunhados (...). Os mais velhos daquele grupo familiar eram pessoas que conseguiam estabelecer uma relação de respeito e de aconselhamento (...). Cabe aos pais, as pessoas mais velhas intervir nas situações de conflitos e aconselhar. Isso era permanente (Entrevista com Katya Vietta, 11 jun. 2014).
\end{abstract}

Em relação aos aspectos da organização social kaiowá, Pereira (2004) destaca a relevância social do fogo doméstico como a unidade mínima de existência humana entre coletivos indígenas e reveladora das relações de gênero tradicionais e contemporâneas.

Ainda segundo este autor, o fogo reúne pessoas ligadas aos laços de conjugalidade que unem mulheres e homens, o de descendência, pelo laço que une pais e filhos, os de pseudoparentesco, através da instituição da adoção de crianças, presente na maioria dos fogos domésticos e quase necessária no fogo dos líderes políticos e religiosos (PEREIRA, 2008, p. 8).

Para Pereira (2008), atualmente o coletivo étnico kaiowá segue morando em fogos e observa a sua importância social e o controle feminino sobre o mesmo:

É possível dizer ainda que na situação atual das reservas, a família extensa ou parentela perdeu muitas de suas atribuições econômicas, políticas, festivas e rituais. O contrário aconteceu com o fogo doméstico que ampliou sua importância e passou a gozar de maior autonomia no interior da organização social, cada vez mais autônomo em relação à parentela e mesmo à comunidade ou reserva na qual se vive. O fogo era e continua sendo controlados por mulheres, o que thes assegura o poder de unir e alimentar seus integrantes. 
Sem mulher não há fogo, reconhecem os Kaiowá (PEREIRA, 2008, p. 9).

Este autor ainda destaca que as intensas transformações entre os coletivos fez com aumentasse a importância social do fogo enquanto módulo de relação, porém realocou a disposição entre os gêneros. As novas configurações de gênero estão contextualizadas na perda de atividades tradicionais masculinas de subsistência, como a coleta, a caça e a pesca, e assim o trabalho assalariado dentro e fora das reservas exercidos por mulheres e homens mudou a questão de status e de prestígio com uma nova dinâmica nos fogos domésticos e, consequentemente, nas práticas sociais. Segundo a pesquisadora Katya Vietta, essas novas configurações são visíveis nas aldeias:

(...) há muitos casos na aldeia de homens que trabalham fora, porque hoje, caça, coleta, pesca, são itens de luxo e eventualmente se consegue isso na aldeia. Não há mais espaço. Não há mais espaço, matos e rios. Os rios estão poluídos e nós somos inacessíveis. Então a produção econômica eventualmente é externa. Essa produção tem que ser buscada fora (Entrevista com Katya Vietta, 11 jun. 2014).

Vietta também aponta para as questões de gênero em relação ao mundo do trabalho nos coletivos indígenas guarani e kaiowá nas aldeias da região:

Aí a tendência é o homem ir buscar pela facilidade que o homem tem de se articular com outra sociedade. Para a mulher sempre é mais difícil por ser mais vulnerável, por conhecer menos os nossos espaços. Então o homem foi trabalhar com os fazendeiros, com os sitiantes. Foi o homem que foi para o corte de cana. É o homem a responsabilidade de dirigir a família. Então quando o homem abandona a família, por qualquer situação, seja por abandono de lar, seja por uma prisão, seja por uma punição, essa família fica desguarnecida e como hoje não existe mais as grandes parentelas, eventualmente você consegue dá algum suporte pra outra esfera da família, a situação é de miséria, é de fome e de dificuldade (Entrevista com Katya Vietta, 11 jun. 2014). 
O homem destes coletivos pode ser considerado dependente do fogo doméstico controlado por mulheres e centrado especialmente na conjugalidade. Mas este fogo também institui e articula a vida social das pessoas que o compõem, impondo ritmo e sentido à vida cotidiana (PEREIRA, 2008). Entre as mudanças em curso, Pereira observa:

No modelo de organização social identificado pelos Kaiowá como tradicional, o casal de articuladores da parentela detém a prerrogativa de interferir de maneira bastante significativa na vida do fogo doméstico. Nas condições atuais das famílias kaiowá residentes na reserva ou fora dela, o casal de articuladores percebe a diminuição de sua capacidade de intervenção na dinâmica de constituição dos fogos. (...) A conseqüência direta dessa transformação é a autonomia crescente conquistada pelo fogo doméstico, sujeito direto de suas próprias escolhas, mas contando cada vez menos com a proteção familiar. Na situação histórica atual, a maioria dos articuladores de parentela acaba por restringir sua atuação a momentos cruciais da vida das pessoas, como nascimentos, casamentos, mortes ou em atritos que envolvem membros de outros grupos familiares (PEREIRA, 2008, p. 10-11).

Pereira observa que a ação de agentes públicos externos também interfere no fogo doméstico, pois estes assumem atribuições que até pouco eram dos articuladores do fogo ou da parentela.

Em linhas gerais pode-se dizer que a intensificação da ação das políticas públicas nas áreas de educação, saúde e assistência social, não apenas realoca a configuração de módulos organizacionais como o fogo doméstico e a parentela, mas cria um ambiente novo, no qual os Kaiowá controlam menos sua própria sociedade. É possível propor que a sociedade kaiowá atual enfrenta um dilema organizacional que se reflete numa espécie de mal estar social, principalmente nas reservas mais povoadas, como Dourados e Amambai, apresentando altos índices de problemas sociais, como violência, delinqüência, etc. (PEREIRA, 2008. p. 10).

Esse menor controle da própria sociedade indígena e a espécie de mal-estar social nestes dois coletivos contribuem com os crescentes índices de violência contra a mulher. Sobre esta questão nos dois aldeamentos, Vietta reforça que: 
Agora o que a gente percebe essa grande família foi desarticulada. Seja em função da redução do espaço (...) onde elas habitam hoje, seja em função da completa escassez e às vezes até ausência de recursos naturais pra garantir a alimentação e também os problemas do próprio contato com os não-índios. Então, acabou levando ao verdadeiro atropelamento dessas famílias e essas referências como o tamoi ${ }^{13},(\ldots)$ elas perdem. Então a família acaba ficando muito vulnerável (Entrevista com Katya Vietta, 11 jun. 2014).

Desse processo de vulnerabilidade são perceptíveis os conflitos de gênero e assim as mulheres indígenas são triplamente vitimadas, ou seja, por serem mulheres, mulheres indígenas e, dentro do grupo étnico, por serem mulheres novamente.

Segundo a Organização das Nações Unidas (ONU), em relatório divulgado em 2010, uma em cada três índias é estuprada durante a vida. Esses dados são corroborantes da assertiva de que as mulheres indígenas são muito vulneráveis à violência. Outra questão que levantamos: numa sociedade patriarcal, que já coloca as mulheres em situação de desigualdade, o que dizer das mulheres indígenas que historicamente foram violentadas e massacradas pelos invasores ${ }^{14}$ ? Que proteção e possibilidades essas mulheres possuem no tempo presente?

De forma geral, a violência doméstica que incide sobre as mulheres é recorrente, conforme destaca Signorelli: "A violência por parceiro íntimo contra mulheres é comum em todos os países" (2012, p.138). Na questão da violência, as mulheres indígenas quase não são lembradas, sendo elas as mais gravemente afetadas por violências múltiplas (SACHI e GRAMKOW, 2012).

Sobre este tema, discutido no Núcleo de Altos Estudos Amazônicos ${ }^{15}$, Simonian observa que:

A problemática da violência praticada contra mulheres indígenas tem sido marginalizada no processo da construção do gênero. Apesar deste desinteresse,

\footnotetext{
${ }^{13}$ Tamoi designa o pai do pai do pai e assim por diante, e eram as pessoas mais velhas de um grupo familiar. O tamoi exercia uma liderança familiar, ritual e política, e conseguia estabelecer uma relação de respeito e de aconselhamento.

${ }^{14}$ Ver Raminelli (1997).

15 O NAEA é uma instituição de Pós-Graduação vinculada à Universidade Federal do Pará, fundado em 1973 com objetivo de estimular e produzir projetos de pesquisas sobre a Pan-Amazônica.
} 
desde muito a violência tornou-se onipresente em todas as sociedades humanas, ao que as sociedades indígenas não ficaram imunes (SIMONIAN, 1994, p.04).

Verdum (2008) também vem alertando para esse tipo de análise específica, pois para ele os pesquisadores “(...) estão cientes dos riscos desse tipo de abordagem, particularmente no que se refere à questão da violência contra a mulher indígena" (VERDUM, 2008, p. 08). Segundo este autor, estamos diante de um tema cuja complexidade implica em dificuldades para propor encaminhamentos e trazer para o debate os direitos humanos e suas violações a partir de uma perspectiva cultural e histórica. Segundo Smith, “(...) as mulheres de cor ... se deparam com um maior número de barreiras quando sofrem violência (ex:: menor atenção da mídia, barreiras de língua, falta de apoio no sistema legal)" (SMITH, 2014, p. 197), e isso demonstra como suas experiências são qualitativamente desiguais das mulheres brancas.

Dessa forma, estes estudos nos mostram as dificuldades que podemos encontrar no âmbito das terras indígenas, pois o enfoque na desconstrução do gênero não poderia levar à desestruturação do modo tradicional de vida destes povos? Em uma situação na qual o agressor foi punido e preso, pergunta-se quem irá assumir as tarefas masculinas? Na pesquisa que realizamos foi possível observar nas próprias falas que as mulheres ou os filhos adultos dos coletivos indígena guarani e kaiowá assumem as tarefas da casa. No excerto que segue, a entrevistada enfatiza os auxílios governamentais quando o marido é preso:

Ah! A mulher. A esposa né? É porque se o marido vai pra cadeia né? Daí já sabe que tem aquele auxílio... tem um auxílio que recebe. Daí vive assim, enquanto o marido tiver lá... é o bolsa família né? Mas na verdade tem alguns marido que não faz falta não quando vai preso. Porque quando tá em casa, ganha um dinheirinho mas só gasta com pinga né? Ou droga né? Daí não faz muita diferença (Entrevista com mulher indígena, Amambai, 17 fev. 2014).

Para muitas entrevistadas, se depender do orçamento da maioria dos homens, o dinheiro é gasto com demonstrações públicas de generosidade, que incluem o consumo de bebidas alcoólicas, e então a 
família carece de alimentação e as mulheres tornam-se vulneráveis à violência.

Nas situações de violações, geralmente não são elas as denunciantes para as instituições que poderiam as proteger, e sim elas ou parentes recorrem ao capitão, o qual decide pela denúncia ou pelo aconselhamento e, eventualmente, pelo trabalho de capina na roça. De modo geral, o capitão encaminha dois tipos de crimes contra as mulheres, ou seja, homicídio e violência sexual, além do suicídio, conforme a fala de um dos capitães:

[...] primeira coisa a denúncia chega aqui em casa né. Agora se der pra resolver os problemas, a gente resolve aqui. Agora se é esse tal de estupro, homicídio, suicídio, isso aí eu posso passar pra delegacia pra poder resolver tudo junto. Porque daí não é sozinho que resolve aqui. A gente resolve tudo junto com a autoridade de fora também, porque a gente sempre acompanha e ele acompanha a gente aqui. Então o estupro a gente não resolve aqui, porque isso aí a gente resolve junto com a autoridade de fora. E suicídio também passa informação pra eles e fazerem o levantamento junto com os capitão da aldeia (Entrevista com capitão, 14 fev. 2014).

Em relação às denúncias e encaminhamentos aos capitães das duas aldeias, algumas mulheres indígenas apontam:

É, porque o capitão resolve pouco né. Conversa né, só fala pra ele não chegar mais agredir a mulher né. Dá um conselho né, mas ele sai dali, ele só ouve, passa do outro lado, chega no outro dia vai piorando mais (Entrevista com mulher indígena, Amambai, $17 \mathrm{fev}$. 2014).

Porque a mulher indígena vai fazer uma denúncia lá na delegacia ou lá no fórum, fala que a cultura não permite, a nossa cultura é diferente do que do que branco. Então a lei existe pra mulher, toda mulher tem direito, mas o que mais fica forte aldeia é a cultura. A mulher pode ser violentada. Pode ser violentada sexualmente, fisicamente, mas a cultura é mais forte. Eu nunca fui na delegacia, mas já ouvi as mulheres falando, que colega assim, vizinho falando, não adianta fazer denuncia. Até agora, os estupradores não vai 
preso (Entrevista com mulher indígena, Amambai, 17 fev. 2014).

Convém salientar que cada aldeamento possui um capitão, mas historicamente não fazia parte da organização social desses coletivos. A figura do capitão esteve associada à demarcação das reservas cuja incumbência era a de estabelecer uma intermediação entre o coletivo indígena e os representantes do SPI, hoje substituído pela Funai. Atualmente o capitão continua sendo legitimado pela Funai e pelos órgãos indigenistas, e sua eleição depende da articulação entre forças políticas das parentelas e de alianças externas. Sobre a imposição deste "líder" nas comunidades indígenas, Vietta destaca que:

Capitão não é uma figura da cultura deles. (...) Com o tempo ela foi incorporada, mas o que caracteriza uma liderança kaiowá? As relações de parentesco. Se ele tem ascensão, se ele consegue conversa, se ele consegue dá conselho, se ele consegue intervir na situação de conflito é porque ele é um parente próximo. (...) o capitão é muitas vezes um desconhecido, muitas vezes é um adversário político. Como que ele vai intervir? E como o capitão vai atender aldeias que tem milhares de pessoas? E o capitão é uma liderança que não tem como dá conta. Não há solução para a atuação do capitão (...) ele quebra todas as lógicas de articulação política tradicional. Então não funciona. Então não consegue ter liderança decente (Entrevista com Katya Vietta, 11 jun. 2014).

Isso significa que o capitão é uma figura alheia às formas de organização de ambas as terras indígenas. Para Vietta (2007), nas últimas décadas, as parentelas lideradas por homens comuns e não por lideranças espirituais (xamãs) não tendem a produzir caciques e, em consequência disso, não promovem as rezas cotidianas, os rituais e as práticas de cura. Esse processo, segundo pesquisa de Vietta, colabora para o aparecimento de inúmeras doenças, o alcoolismo, violência e suicídio.

Conforme se observou a campo, as mulheres indígenas percebem as limitações para denunciar a violência doméstica perante o capitão, e quando o fazem sofrem incompreensão e pressões fortes no seu meio familiar e comunitário, conforme as falas abaixo: 
Não fiz denúncia porque na, na época eu, eu não sabia de nada né. Pra mim que era normal né. Tudo que eu levava assim normal né. Pra mim nunca pensei assim de denunciar né. Que era coisa grave que precisava denunciar né. Mas a minha mãe me ajudava muito né. Ela me apoiava muito e que um dia vai acabar né, e um dia ela se separou dele e acabou (Entrevista com mulher indígena, Amambai, 17 fev. 2014).

Elas se sentem ameaçada pelo marido, né? Porque se denunciar, né, tem medo do marido, né, matar ela, né? Tem medo de piorar as coisa, né? Então elas preferem se calar (Entrevista com mulher indígena, Amambai, 17 fev. 2014).

Em grande parte das falas das mulheres percebe-se que preferem não denunciar, pois o medo impera, principalmente pela desproteção dos filhos, pois entendem que a justiça indígena não lhes garante proteção e tampouco a justiça não indígena. Com a morte da mãe, geralmente os filhos estarão desamparados. A preservação da família com filhos menores é fundamental para a maioria destas mulheres.

Nas circunstâncias atuais, muitas mulheres indígenas kaiowá e guarani trabalham em atividades remuneradas, principalmente como professoras, agente de saúde, serviços gerais e empregadas domésticas. Das entrevistadas da reserva Amambai, todas trabalham na escola local e entre as mulheres da reserva Limão Verde, a maioria delas não exerce atividade remunerada. O salário é considerado por elas como uma boa remuneração para o padrão econômico do grupo. Com isso a mulher adquire poder e autonomia no espaço doméstico e na vida econômica do grupo. Com a remuneração, elas agregam vantagens sociais no coletivo, principalmente se o companheiro não dispõe desta forma de trabalho remunerado e permanente, como das mulheres servidoras públicas. Isso realoca as relações de gênero, pois o homem passa a ocupar uma posição inferior. Estas novas configurações podem dar origem a conflitos de gênero.

Para Pereira (2008), observa-se que a atuação feminina kaiowá em relação à economia doméstica é importante para o bem-estar do grupo:

O compromisso feminino socialmente estabelecido com o bem-estar dos integrantes do fogo favorece, segundo 
a concepção kaiowá, uma administração mais racional e previdente dos recursos, enquanto os homens tendem sempre ao excesso e ao esbanjamento. (...) É por isso que as mulheres procuram circunscrever a participação do homem na economia basicamente enquanto produtores, o dinheiro ganho deve ser destinado à mulher, encarregada da compra e distribuição dos produtos, quando os homens e os filhos entram no final da cadeia como consumidores de produtos distribuídos pelas mulheres (PEREIRA, 2008, p. 15).

Destarte, a inclinação de alguns homens ao esbanjamento e aos excessos pode também ocorrer em relação ao consumo de bebida alcoólica e inclinar-se ao uso da violência contra as mulheres.

Essas interferências têm um grande impacto nessas comunidades indígenas, gerando a violência. Simonian (1994) e Rodrigues (1999)16 reforçam que esse problema está presente em todas as sociedades ameríndias. "[...] [A]lcoolismo é um problema central atualmente [...] contribuindo para aumentar a violência entre os índios, o suicídio entre os mais jovens e preconceito da sociedade envolvente em relação à comunidade indígena" (RODRIGUES, 1999, p. 02). Em muitos coletivos indígenas, o consumo de bebidas fermentadas era tradicional e fazia parte da construção da coletividade para reafirmar os valores do grupo, estabelecendo também desta forma uma relação com a sua cosmologia. A maior presença de bebidas destiladas ocorreu a partir do final do século passado, XX, reforçada pela instalação de alambiques dentro das áreas indígenas ou nas proximidades.

Conforme discute Pereira (2008), a propensão dos homens ao excesso pode se expressar tanto na generosidade quanto na violência e, em geral, é intensificada no caso do consumo de álcool. Nas aldeias ocorrem também situações nas quais o casal consome bebida alcoólica com frequência, e a tendência são as privações econômicas e alimentares, nas quais os demais integrantes da família são vitimados. Pereira salienta ainda que:

O consumo regular de bebidas alcoólicas pela mulher é tido como falha grave e implica na perda ou diminuição da prerrogativa de organizar a vida familiar, enquanto o consumo de bebidas alcoólicas pelos homens é mais

${ }^{16}$ Aldeias Karajá e Javaé. 
tolerado, desde que eles não cometam excessos graves como violência familiar, motivo justificado para a separação do casal. (...) A importância primordial da mulher como articuladora do fogo se evidencia quando ela passa a consumir bebida alcoólica e imediatamente o fogo se desorganiza, o mesmo não acontecendo necessariamente no caso de só o homem fazer o consumo excessivo de bebidas (PEREIRA, 2008, p. 19).

Conforme Simonian,

as bebidas são vistas como uma solução para os problemas recorrentes de um cotidiano sem esperanças. [...] O estupro e as lesões corporais fazem parte do dia-a-dia atual destas mulheres, vítimas que são de esposos e parentes (SIMONIAN, 1994, p. 22).

Para Simonian, o alcoolismo é o principal vilão, precursor de quase toda violência contra as mulheres indígenas, e afirma ainda que: "Onde a incidência do alcoolismo é grande tal tendência vem, proporcionalmente aumentando" (1994, p. 22). Maristela Torres reforça que:

a maioria dos casos de agressões físicas às mulheres é praticada pelos homens quando estão bêbados, muitos ficam extremamente agressivos e podem bater em quem encontrar pela frente, até mesmo em suas próprias mães (TORRES, 2010, p. 04).

Elas tornam-se as vítimas preferenciais por serem mais vulneráveis e ficam em situação de desigualdade 17.

O alcoolismo e drogas ilícitas no entorno e dentro das aldeias fazem com que as mulheres indígenas se tornem o principal alvo da violência masculina. Isso é perceptível na maioria das falas de mulheres guarani e kaiowá:

Eu acho que é álcool, álcool alcoólico né, e droga também. Tem muito homem que usa droga né. $E$ a pessoa drogada não sabe né. Acho que não tem amor próprio. Próprio dele mesmo. Chega com a agressão né. $E$ as maioria são os bêbados né (Entrevista com mulher indígena, 17 fev. 2014). Né?

\footnotetext{
${ }^{17}$ Sobre a questão do alcoolismo e uso de drogas e violência contra mulheres indígenas, veja-se Torres (2010).
} 
Olha, primeiramente é o álcool né. A pinguinha que eles tomam muito né. $E$ o outro é a infidelidade do marido né (Entrevista com mulher indígena, 17 fev. 2014).

O fato que leva à violência, é por causa da bebida alcoólica, e além do mais outras drogas que entram e essas levam a muita violência contra as mulheres (Entrevista com mulher indígena, 17 fev. 2014).

Que às vezes a pessoa fuma e não sabe fumar e já vai fazendo. Aí quando é o outro dia fala assim: eu fiz porque eu tava fumando, é isso que vai (Entrevista com mulher indígena, 17 fev. 2014).

[...] porque homem pra fazer coisa, porque agora tem mais pessoa que diz que mexe com droga por aí né. Isso que dá mais coragem de chegar em casa com alguma coisa para fazer né (Entrevista com mulher indígena, 17 fev. 2014).

Em suas falas, muitas mulheres citam o ciúme como uma das motivações para que ocorram brigas e agressões físicas entre marido e mulher. Geralmente as mulheres desses dois coletivos étnicos são consideradas ciumentas, mas os conflitos entre os casais, em função do ciúme, faziam e fazem parte do cotidiano, porém em nada se parecem com a questão da violência doméstica hoje, que constitui uma das principais problemáticas advindas a partir do contato com a sociedade não índia. Assim, em suas falas, o ciúme, o adultério, o consumo de bebidas alcoólicas e o uso de drogas atuam quase sempre em conjunto nos conflitos de gênero:

Ah, a maioria que acontece com as mulheres?! Na aldeia, o ciúmes e a própria mulher também tem ciúmes do marido e aí que acontece?! E esse fato acontece mais do que do que além das outras coisas. Porque tem desconfiança, tem muita traição, tem [pausa] é isso que acontece mais de $10 \%$ (dez por cento) acontece mesmo a parte através dessa violência. Por causa de ciúmes (Entrevista com mulher indígena, 7 mar. 2014).

Olha, primeiramente é o álcool né. A pinguinha que eles tomam muito né e o outro é a infidelidade do marido né. Acontece muito. Quando o marido acha, que encontra uma outra mulherzinha, rabinho de saia, já 
sabe como é que é né. Já vê a esposa como uma mala na vida deles né, que tá atrapalhando né. Então essas duas coisas né, o álcool e a infidelidade do marido (Entrevista com mulher indígena, 7 mar. 2014).

No caso chega na bebida né. Ou vai lá na rua beber com os amigos. Chega lá o que acontece muito na aldeia também, tem muito as mulherzinhas, assim, mulherzinha do mundo, biscatinha né. Aí se encontra com uma então que fala sua mulher fez isso, fez aquilo. Eles usa muita mentira no meio. Aí ele fala que fulana falou que você fez isso, então é porque você fez. Daí já vem espancamento e às vezes chega até matar né (Entrevista com mulher indígena, 7 mar. 2014).

Vietta (2007, p. 452) explica que, nas últimas décadas, o casamento geralmente foi monogâmico, inclusive entre lideranças. Com a monogamia, é possível perceber que o ciúme torna-se um estado emocional definido como um conjunto de emoções desencadeadas por sentimentos de alguma ameaça à estabilidade ou à qualidade de um relacionamento íntimo valorizado. Soyka entende que, nas sociedades em que a monogamia tornou-se um imperativo social e cultural, o ciúme foi concebido como uma proteção para a família. O sentimento de ciúme foi construído culturalmente como uma reação frente a uma ameaça (SOYKA, 2005, p. 37).

Nos casos de violência contra as mulheres, uma das formas de controle em relação à fidelidade na conjugalidade é a fofoca ou o mexerico. Estas também podem levar a informação sobre a violência contra mulheres ao capitão ou algum líder espiritual para os aconselhamentos ao marido e esposa. Segundo Almeida (1991), a fofoca ou o mexerico conformam aspectos constitutivos do cotidiano. É uma prática que tem por objetivo mudanças de comportamento. Na maioria dos casos, funciona para afirmar posição frente a outros indivíduos, mas também pode se tornar uma informação manipulada, ou seja, de manejo de situações sociais com o objetivo de atingir opositores, marcando, ao mesmo tempo, a posição do discursante (ALMEIDA, 1991, p. 272).

A fofoca, enquanto um gênero de comunicação informal e mecanismo para priorizar e proteger interesses individuais ou de grupos que partilham a informação, pode ser destinada a diferentes objetivos. Para Almeida, “(...) servem de qualquer forma como controle social local. 
O mexerico pode tornar-se sanção direta ou informal sobre pessoas ou entidades em situações nas quais não se pretende arriscar um embate frontal e aberto" (ALMEIDA, 1991, p. 273). A fofoca também pressupõe um mecanismo de comunicação conhecido por todos, e passível de tornar-se um julgamento de comportamento. Essa forma de comunicação pode tanto unir como provocar rupturas em uma comunidade e grupos familiares. Em coletivos indígenas, um incidente aparentemente inexplicável pode aparecer como sendo obra de feitiço, conforme explica Almeida:

Como não há provas, o fenômeno se converte em realidade, concretizando-se através do mexerico. Criase uma verdade que pode provocar a separação e 0 translado de famílias que se sintam prejudicadas. A fofoca informa, mas é informação conotada, com objetivo político e destarte configura-se como uma forma de política subliminar (ALMEIDA, 1991, p. 273).

Nestes coletivos, os casamentos se desfaziam somente com a morte de um dos cônjuges, mas atualmente a fidelidade não é mantida com a mesma facilidade. Em ambos os aldeamentos, o ciúme e o adultério são geradores de conflitos, pois a mulher indígena casa uma só vez ou esposa novamente devido à viuvez.

Isso sempre foi ponto de conflito. Você tem até hoje, em algumas aldeias famílias que tem rixas históricas. Se você vai lá e conta, são gerações e gerações e gerações atrás que alguém traiu alguém e aí criam conflitos. (...) Tradicionalmente o kaiowá casa uma vez só. Não havia separação. A separação não era algo permitido. (...) Só havia um segundo casamento quando havia a viuvez. Então, a obrigação da fidelidade, do companheirismo, enfim, isso é muito cobrado da mulher kaiowá (Entrevista com Katya Vietta, 11 jun. 2014).

Nas circunstâncias atuais, a dissolução do casamento é tolerada e geralmente está relacionado ao adultério, consumo de bebidas alcoólicas, ciúmes e a falta de provimento econômico do homem (VIETTA, 2007, p. 452). Cabe acrescentar que a violência doméstica pode ser um dos principais motivos para a dissolução conjugal, pois 
agrega um conjunto de disposições conflitantes citadas nas entrevistas e pela bibliografia consultada.

\section{Considerações finais}

O último século trouxe profundas transformações na vida kaiowá e guarani, e a análise da violência doméstica contra as mulheres indígenas em Amambai (MS) precisa levar em conta esta perspectiva histórica para contornar uma leitura simplificada daquela realidade.

Sabe-se que as mulheres indígenas têm sido vítimas de ações violentas no contexto de suas próprias comunidades, no contato com a sociedade branca e naquele imposto a partir do colonialismo europeu. A crescente violência contra as mulheres nos aldeamentos tem relação direta com as perdas territoriais e o consequente esboroamento dos vínculos sociais, das práticas políticas, econômicas e religiosas, perdas estas que são geradoras de miséria e violências múltiplas.

De modo geral, as violências perpetradas contra as mulheres destes coletivos étnicos são decorrentes de processos de violações de seus povos, as profundas modificações com o contato não indígena, recolhimento das populações em reservas pequenas, a degradação da paisagem natural e a introdução de drogas e bebidas alcoólicas nestas comunidades. Retomando o já dito, também a perda de atividades tradicionais masculinas de subsistência, como a coleta, a caça e pesca, e assim o trabalho assalariado dentro e fora das reservas exercidos por mulheres e homens mudou a questão de status e de prestígio com uma nova dinâmica nos fogos domésticos e, consequentemente, nas práticas sociais, as quais podem produzir os conflitos de gênero.

As mulheres indígenas das reservas Limão Verde e Amambai relatam essa forma de violência com muita tristeza e às vezes indignação, e sabem que está relacionada principalmente à ingestão de bebidas alcoólicas pelos companheiros. Para muitas mulheres, a conjugalidade implica na manifestação de generosidade e companheirismo, e a violência contra elas quebra essa relação. As violações contra as mulheres indígenas desarticulam as relações de 
gênero baseadas na reciprocidade e mutualidade. A pergunta que se faz é: até quando elas vão ficar submetidas a esses atos de violência?

Como já comentado, muitas vezes a ingestão de bebidas alcoólicas relaciona-se com a propensão dos homens ao excesso, que pode se expressar tanto na generosidade quanto na violência e, em geral, é intensificada no caso do consumo de álcool. Nas aldeias, o consumo de bebidas alcoólicas pelos homens é mais tolerado. E, nesse caso, as decisões pelo seu consumo estão nas mãos masculinas. Haverá algum dia interesse dos homens desses coletivos em promover mudanças? Com a mudança de estilos de vida advindos com a entrada de elementos da cultura ocidental que interferem negativamente em suas estruturas culturais e sociais, algumas leis, seja dos coletivos ou não indígenas, não podem mais servir como instrumento de produção de dor e tristeza nestes coletivos étnicos, principalmente em relação a mulheres e crianças.

Diante do esgarçamento das relações sociais nestes coletivos étnicos, as respostas devem vir a partir de suas discussões, reflexões e tomadas de decisões. Para muitas mulheres indígenas vitimadas e outras pessoas entrevistadas e conhecedoras dos conflitos, como possíveis saídas para as violações deve-se ouvir os mais velhos, reestruturar ritos e rever as leis próprias. Esse processo envolve a participação de todos nos coletivos, principalmente das mulheres, pois, nas entrevistas, elas querem mudanças e têm sabedorias acumuladas para contribuírem na restauração dos fios de esperança e, de maneira conjunta, tecerem e reordenarem instâncias próprias que garantam maior proteção, dignidade e qualidade de vida, não somente para as mulheres, mas para as crianças e homens também.

\section{Referências bibliográficas}

ALMEIDA, Rubem Thomaz de. O Projeto Kaiowá Ñandeva: uma experiência junto aos Guarani-Kaiowa e Guarani-Nandeva contemporâneos do Mato Grosso do Sul. 1991. 465 f. Dissertação (Mestrado em Antropologia Social) - Museu Nacional, Rio de Janeiro, [1991]. 
BOBBIO, Norberto; MATTEUCCI, Nicola; PASQUINO, Gianfranco. Dicionário de Política. Brasília: UnB, 1998.

BRAND, Antonio. O impacto da perda da terra sobre a tradição Kaiowá/Guarani: os difíceis caminhos da palavra. 1997. 390 f. Tese (Doutorado em História) - Pontifícia Universidade Católica do Rio Grande do Sul, [1997].

FELIPE, Guilherme G.; PAZ, Carlos. Entrevista com Graciela Chamorro. Espaço Ameríndio, Porto Alegre, v. 5, n. 2, p. 143-158, 2011.

MELIÁ, Bartomeu; GRÜNBERG, G.; GRÜNBERG, F. Etnografia Guarani delParaguay Contemporâneo: Los Pai-Tavyterã. Suplemento Antropológico, Assunción, v. 11, p. 151-295, 1976.

OVERING, Joanna. Elogio do Cotidiano: a confiança e a arte da vida social em uma comunidade amazônica. Mana, Rio de Janeiro, v. 5, n. 1, p. 81-107, 1999.

PEREIRA, Levi M. Parentesco e Organização Social Kaiowá. 1999. 233 f. Dissertação (Mestrado em Antropologia Social) - Universidade Estadual de Campinas, Instituto de Filosofia e Ciências Humana, [1999].

Imagens Kaiowá do Sistema Social e seu Entorno. 2004. 345 f. Tese (Doutorado em Antropologia Social) - São Paulo/SP, USP, [2004].

A criança kaiowa, o fogo doméstico e o mundo dos parentes: espaços de sociabilidade infantil. 32 Encontro da ANPOCS, Caxambu, Minas Gerais, 2008.

RAMINELLI, Ronald. Eva Tupinambá. In: DEL PRIORE, Mary (Org.). História das Mulheres no Brasil. São Paulo: Contexto, 1997. p. 11-44.

RODRIGUES, Patrícia de Mendonça: O surgimento das armas de fogo: alteridade e feminilidade entre os Javaé. Revistas Estudos Feministas, Florianópolis, v. 7, p. 35-49, 1999.

SACHI, Ângela; GRAMKOW, Márcia M. (Org.). Gênero e Povos Indígenas. Rio de Janeiro: Museu do Índio, 2012.

SERAGUZA, Lauriene. Cosmos, corpos e mulheres Kaiowa e Guarani de Aña à Kuña. 2013. Dissertação (Mestrado em Antropologia) - Dourados, UFGD, [2013].

SIGNORELli, Marcos Claudio; TAFT, Angela; PEREIRA, Pedro Paulo Gomes. Violência por parceiro(a) íntimo(a) contra mulheres e cuidado em saúde na Austrália: cartografando o cenário. Ciência e Saúde Coletiva, Rio de Janeiro, v. 17, n. 4, p. 10371049, 2012. Disponível em: http://www.scielo.br/scielo. Acesso em 16/04/2013. Acesso em: 22 jun. 2015. 
SIMONIAN, Ligia T. Lopes. Mulheres Indígenas vítimas de violência. Papers do Naea, n. 30, 1994.

SMITH, Andréa. A Violência Sexual como uma Ferramenta de Genocídio. Espaço Ameríndio, Porto Alegre, v. 8, n. 1, p. 195-230, 2014.

SOYKA, Michael. Wenn Frauen töten. Stuttgart: Schattauer, 2005.

TORRES, Maristela S. Um olhar sobre a violência intrafamiliar em aldeias Karajá. $2010 . \quad$ Disponível em: http://www.fazendogenero.ufsc.br/9/resources/anais/1266957895_ARQUIVO_Umolhar sobreaviolenciaintrafamiliaremaldeiasKaraja.pdf. Acesso em: dez. 2013.

VERDUM, Ricardo. Mulheres Indígenas, Direitos e Políticas Públicas. Brasília: INESC, 2008.

VIETTA, Katya. Tekoha e te'y guasu: algumas considerações sobre articulações políticas Kaiowá e Guarani a partir das noções de parentesco e ocupação espacial. Tellus, Campo Grande, v. 1, n. 1, p. 89-102, 2001.

Histórias sobre terras e xamãs kaiowa: territorialidade e organização social na perspectiva dos Kaiowa de Panambizinho (Dourados, MS) após 170 anos de exploração e povoamento não indígena da faixa de fronteira entre o Brasil e o Paraguai. 2007. 512 f. Tese (Doutorado em Antropologia) - São Paulo, USP, [2007].

Recebido em: 16/02/2015* Aprovado em: 07/05/2015* Publicado em: 30/06/2015 